Article

\title{
Determination of Material Characteristics and Shear Wave Velocity of Volcanic Sediment Layer of Mount Samalas Using MASW Technique
}

\author{
Hiden ${ }^{1, *}$, Teguh Ardianto ${ }^{2, *}$, Suhayat Minardi ${ }^{3, *}$, Alfina Taurida ${ }^{4}$, Muhajirah 5 \\ 1 Physics Program Study, University of Mataram, 83125 Indonesia; hidenpamula@gmail.com (H.H) \\ 2 Physics Program Study, University of Mataram, 83125 Indonesia; teguh.ardianto@unram.ac.id (T. A) \\ 3 Physics Program Study, University of Mataram, 83125 Indonesia; suhayat.minardi@unram.ac.id (S.M) \\ 4 Physics Program Study, University of Mataram, 83125 Indonesia; alfina_taurida@unram.ac.id (A.T) \\ 5. Geotechnic, Civil Engineering, University of Mataram, 83125 Indonesia; muhajirah_mstf@yahoo.com (M.M) \\ * Correspondences: hidenpamula@gmail.com; Tel.: +6281339579193; \\ teguh.ardianto@unram.ac.id; Tel.: +628113964205; \\ suhayat.minardi@unram.ac.id; Tel.: +628119212265
}

\begin{abstract}
The application of geophysical methods for the characterization of geomorphologic subsurface features has become very popular in recent years. Convential geophysical applications on undifferentiated and weathered slopes have been less effective. Multichannel analysis of surface waves (MASW) is a new hope for the solution of the problem. MASW methods was used to the first step in order to reconstruct the ancient eruption of Mount Samalas. MASW was applied to the remnants of ancient volcanic sediment on Lombok Island to determine the physical and physical characteristics of seismic subsurface features. This paper is also discussion the application's capabilities of the MASW method on undifferentiated and weathered volcanic deposits on the slope area and classified them. The results of the research show that MASW technique is powerful in characterizing and delineating the stratum of the layers of undifferentiated and weathered volcanic precipitation areas. MASW is able to predict subsurface structures, especially for shallow and thin layers and presenting site class information for internal structure (vertical resolution). Based on $\mathrm{S}$ wave velocity structure, undifferentiated and weathered volcanic layer, genes are classified into site class C, D, and E. In the future, this method will completed with combination of other geophysical method and parameters variation (frequency and spaces) for isopach mapping of volcanic sediment and then analysis of ancient volcanic eruption dynamics.
\end{abstract}

Keywords: undifferentiated and wheathered deposits, thin layers, vs characterization, MASW. 


\section{Introduction}

The application of geophysical methods for the characterization of geomorphologic subsurface features has become very popular in recent years. For example, how geophysical methods can be used to identify multidimensional, differentiate, and the characteristics of glacial landforms, aeolian volcanic, and tectonic in relation to different survey objectives [1]. So far, conventional geophysical applications on undifferentiated and weathered slopes have been less effective. Multichannel Analysis of Surface Waves (MASW) is a new hope for the solution of the problem. Surface wave techniques such as MASW, have been applied in geomorphological studies, show that the method is accurate, and similar seismic data can be analyzed by refraction techniques for the same location [2]. The MASW application to identify $S$ wave velocity $\left(v_{\mathrm{s}}\right)$ in the sloped terrain area. Using MASW to define onedimensional (1D) $v_{s}$ profiles on the bridge foundation and controls adjacent zones to create base stability (baseline) of the $v_{\mathrm{s}}$ situ profile [3].

More advanced computing and equipment capabilities help users, timeefficient, and costly, deliver high-resolution data processing and results. Again, the parameter measurements represent some of the mechanical and physical characteristics of the subsurface. On the contrary each method has its deficiencies and limitations, mainly due to the lack of contrast between subsurface physical properties.

MASW as a surface wave method, is a very powerful tool for characterizing layers near the surface. MASW can accurately reflect, soil-bedrock interface [2]. To solve the problem, we perform data acquisition with two source-offsets and two different end shots to know the thickness variation of deposit layer. The combination of the dispersion curve results from both offsets to increase the bandwidth and the resolution of both inner and shallow layers.

The MASW method was used to determine the physical characteristics of seismic i.e. $v_{\mathrm{s}}, v_{\mathrm{p}}$, and thickness, in addition to the physical characteristics of undifferentiated and weathered volcanic deposits on Lombok Island, Indonesia. We conducted a multi-scale investigation to identify the characteristics of each layer of volcanic sediment and to verify the results of the MASW method with outcrops in the field.

\section{Materials and Methods}

\subsection{Material}

\section{Geological Study Area}

Lombok Island, especially on the North side of Mount Rinjani, (Figure 1). Based on local history (Babad Lombok) there has been an eruption at the same time [4]. The horrifying eruption created the caldera named Segara Anak and pumices produced. The pumice deposits which can be found in all parts of Lombok Island. We found several outcrops with different physical characteristics in the southern region of Mount Samalas and Mount Rinjani, so we chose the area as a research location (Figure 1).

[5] found that the sediment type of Mount Samalas possesses massive, unconsolidated, unsorted, and multi-model granule size characteristic. Three basic types of classtic sediment of volcanic are: falls, surges, and PDC sediments [6]. The characteristics of falls sediment: topographic coated, parallel bedding, well-organized, and opened gradation. While the characteristics of sediment flow: limited topography, unorganized, and opened gradation. PDC deposition's characteristics are separated topography, across-bedding, medium-opened gradation. PDC sediment includes scoria (bigsized mafic), pumice (big-sized silica), and ash (fine sand). Falls sediment: very close to vent, fall vertical particles and reach broader scope. This kind of deposit can be found almost everywhere and has the same thickness in some distances and direction from the vent.

Volcanic classtic deposits of Mount Samalas can be found in all parts of Lombok Island [5]. The eruption of the eruption of Mount Samalas, particularly in the South and Southwest regions, has composition: Alluvium (Qa), Young volcanic rock (Qhv), Lokopiko (Qvl), and Kalibabak Formation (Tqb) (Figure 1). The volcanic sediment constructed the stratigraphy of Lombok 
Island, particularly in Benang Kelambu, Benang Stokel, until to the Barabali in the South. The sediment is also found in the southwest of the source from Sedau, Sesaot, to the Penimbung (Figure 1). Formation Qvl is the inseparable ancient volcanic rock and Quaternary Holocene-Pleistocene age constructed the stratigraphy of the area. Types of the rock are andesitic, alluvial, and sand sediment [7]. The composition of volcanic classtic of Tqb and Qvl formation is found in the western and southern part of Mount Samalas especially in Narmada-Sedau, Benang Kelambu to Barabali, and Sesaot to Lingsar.

\section{Surface wave methods}

An important element in determining seismic design criteria for engineering sites is the measurement of seismic wave velocities (Vs). Vs and other physical properties of the earth's material can be used to determine its elastic properties and therefore the seismic response underlies the theoretical load caused by the local earthquake. The relationship of material properties in this case is the velocity of shear and compressive waves, as are the density and non-linear properties of both soil and rock. Although the most influential on ground motion is the material variation in the depth of tens to hundreds of meters from the surface [8].

Currently, site characteristics are often specified by a single number, e.g. Vs30, S wave velocity up to $30 \mathrm{~m}$ from the surface. This number is well known as building codes [911] for classifying situ, knowing the situ amplification characteristics and fundamental periods of soil profiles. Vs is also used as a parameter of situ classification in building the attenuation model with the depth of engineering stone. Moreover, $\mathrm{Vs}$ is the fundamental input parameter for dynamic analysis. If Vs is directly related to the shear modulus, then this is also very important in geotechnical and geo-enviromental. In order to determine Vs30 from the surface, an in-situ seismic method is used to obtain Vs as a depth function.
In-situ geophysical methods have been used extensively to present information on under surface characteristics for engineers and geologists to evaluate the properties of soil deposits and rock formations. Finally geophysical methods have been developed in terms of theory, equipment, and computing, to present subsurface information accurately, quickly, and inexpensively. Accuracy of subsurface information contributes to the security and resilience of the population. In the future, it is expected that geophysical methods, especially MASW techniques, can be applied well to volcanic deposits, especially in undifferentiated and weathered formations. So that surface geophysical method can be an alternative method in analysis of ancient volcanic dynamics and prediction of volcanic eruption and hazard assessment due to volcanic eruption.

Recent surface wave uses have been developed in geomorphological investigations [2, 12, 13], particularly MASW [14]. The MASW method has become popular because of its efficiency and capability to characterize soil profiles by inversion speed [15]. Surgeon surface waves propagate through the earth's layer of shortwave, high frequencies propagate in shallow areas. While long wavelength waves, low frequencies propagate through shallow and deep regions, following the characteristics of Rayleigh waves. The structure of Vs can be estimated by inversion analysis of various wave propagation velocities with respect to frequency.

Surface wave method has become the most commonly used seismic technique to estimate the structure of ground Vs velocity, because it is natural, non-invasive, and its acquisition and data processes more efficient [16]. The surface wave method is based on the natural dispersion curve of the Rayleigh wave in layered media (Fig. 2) to obtain the subsurface shear wave velocity profile. 


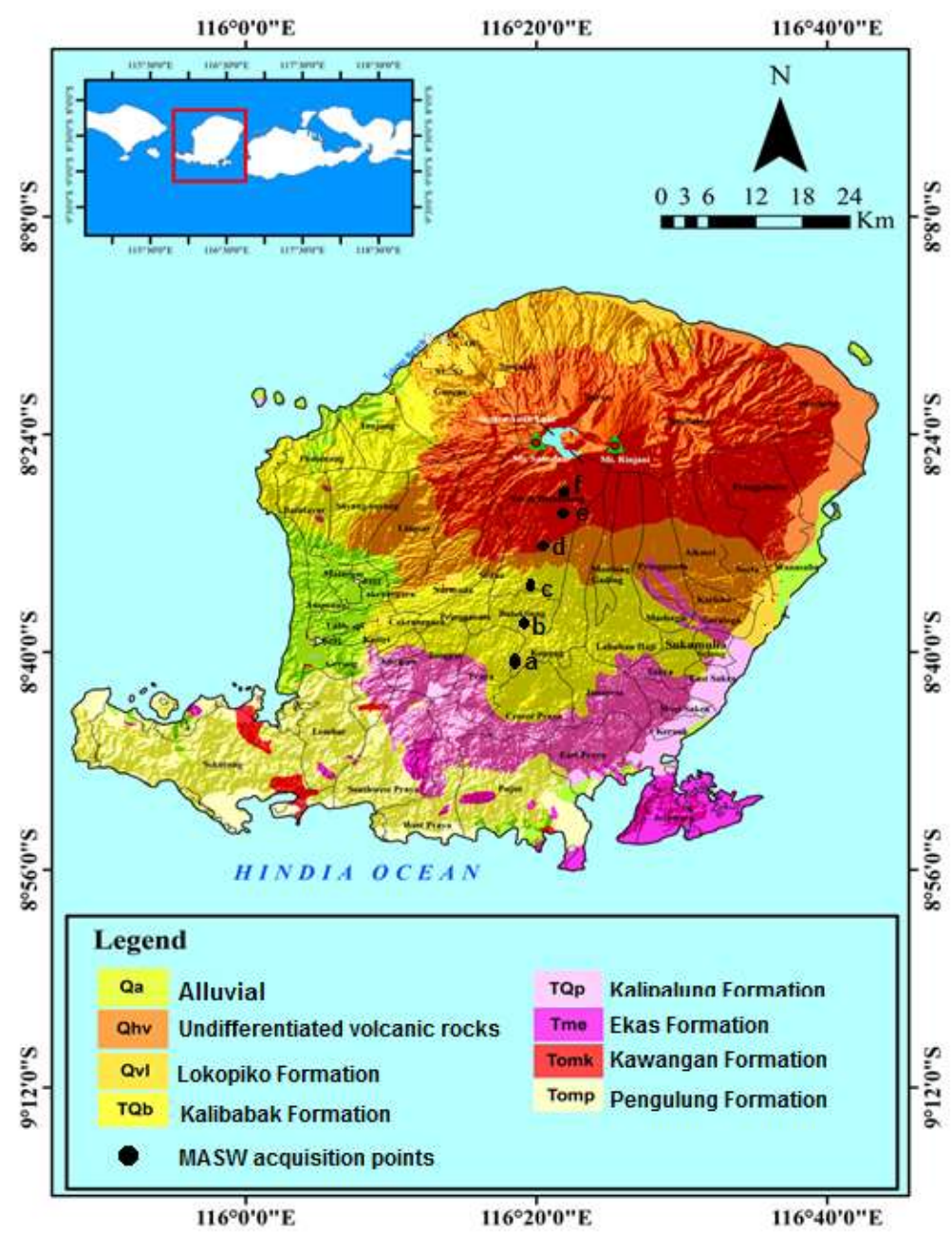

Figure 1. Geological map of Lombok Island and the study location. Mount Samalas and Mount Rinjani, both indicated with green fill triangle, as a source of Sediment volcanic [Modified after 7].

Surface waves depend on the frequency, density and stiffness of the subsurface material. The waves propagate through different depths and a certain phase velocity. The dispersion curve is an interpretation of the different modes or harmonics of surface waves propagating through the layered media (Fig. 2). MASW is an excellent choice for estimating shear wave velocity [17]. The assumption on the MASW method is the authenticity of the material near the surface and treated simply as a layered earth model with no lateral variation in elastic properties, so that it can provide information about variations of elastic properties in the vertical direction (Fig. 2).

Rayleigh waves are the result of interference of $\mathrm{P}$ and SV waves of each vertical component and surface wave radial. Rayleigh waves are one type of surface wave that runs along free surfaces such as earth-air or earthwater interfaces. Particles of the fundamental Rayleigh wave modes in a homogeneous medium move from left to right with elliptic shape and clockwise along the free surface. Relatively low speed, low frequency and high amplitude are the characteristics of Rayleigh waves. The amplitude of the wave motion decreases exponentially to the depth (Fig. 2). When it reaches a considerable depth, the surface wave becomes the plane (Planar). The motion of the particle is limited by the vertical plane corresponding to the direction of wave propagation [18]. Likewise, the depth of $S$ 
wave propagation is a function of wavelength

[14].

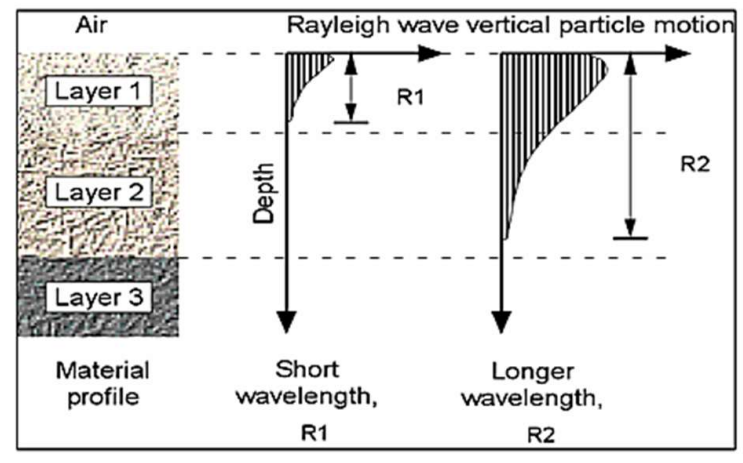

Figure 2. Principle of geometric dispersion [19].

\subsection{Methods}

In this study a survey was conducted using Multi-channel Analysis of Surface Waves (MASW) technique [14]. The data acquisition uses a multichannel shot gather similar to conventional common midpoint (CMP) in the reflection seismic survey. The experiment was setup using a $5 \mathrm{~kg}$ sledgehammer source with 24 geophones (active station), and Spiked vertical geophone frequency $10 \mathrm{~Hz}$. The survey used a moving source, a distribution of 24 geophones and 2 shot offsets and 2 end shots of each forward and reverse along the line, as well as fixed offsets (Fig. 3 and Table 1). In this MASW survey, the source offset distance to the receiver is mounted on one-fourth of the profile line length and the end shot distance at half the geophone spacing of the first geophone (Figure 3). Then the shot position is moved to mid-between each geophone so that the total shot position is 27 . Shot in each position is done 3 stack to increase the Signal to Noise (S / N) Ratio.
Recording length and sampling rate in sets 2

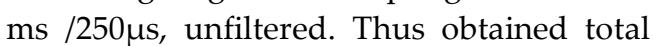
recording 135 data $(5 \times 27$ = number of stack * number of positions) every single line.

In the MASW method, the body wave energy and the different modes of surface waves can be distinguished by applying the frequency-slowness (f- $p$ ) process. Synthetic dispersion profiles on the MASW method can be performed by numerical methods and finite methods in the frequency and time domain [20, 21]. The accuracy of the dispersion curve extract is a very important element of the MASW method. Therefore, the selection of the optimum acquisition parameter is an important step before another step of processing. The frequency range and range of phase velocities of the ground roll need to be determined by analyzing the data along the line. These two ranges are important constraints to extract dispersion curves from shot gather to eliminate noise recordings and to help define model layer thickness [22].

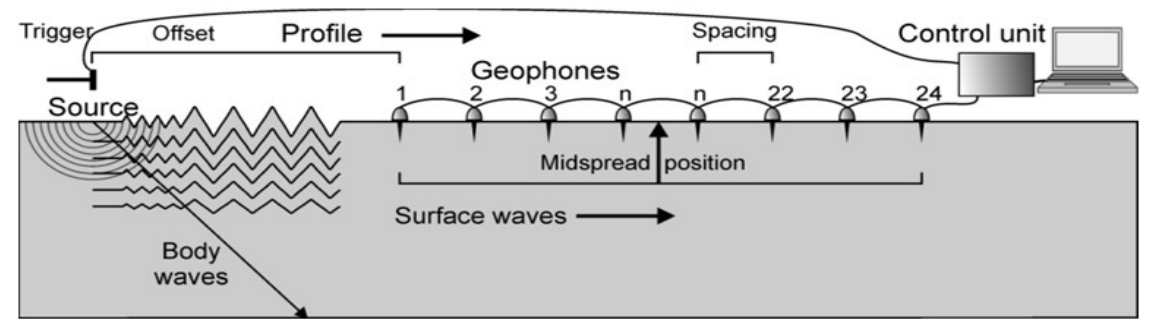

Figure 3. Geometry of measurement MASW and Refraction Survey line 
Table 1. Parameter Geometry measurement of MASW Methods in the Southern Region of Mount Rinjani

\begin{tabular}{lcccccc}
\hline \multicolumn{1}{c}{ Lokasi } & $\begin{array}{c}\text { Profil } \\
\text { length } \mathbf{( m )}\end{array}$ & $\begin{array}{c}\text { Channel } \\
\text { number }\end{array}$ & $\begin{array}{c}\text { Max. Offset } \\
(\mathbf{m})\end{array}$ & $\begin{array}{c}\text { End shot } \\
(\mathbf{m})\end{array}$ & $\begin{array}{c}\text { Spacing } \\
(\mathbf{m})\end{array}$ & Stacks \\
\hline Benang Kelambu & 23 & 24 & 23 & 1 & 2 & 3 \\
Benang Stokel & 23 & 24 & 23 & 1 & 2 & 3 \\
Aik Berik & 17.5 & 24 & 17.5 & 0.75 & 1.5 & 3 \\
Teratak & 23 & 24 & 23 & 1 & 2 & 3 \\
& 11.5 & 24 & 5.75 & 0.25 & 0.5 & 3 \\
Dasan Baru & 23 & 24 & 11.5 & 0.5 & 1 & 3 \\
Barabali & 17.5 & 24 & 17.5 & 0.75 & 1.5 & 3 \\
\hline
\end{tabular}

Although the range of interesting frequencies and spatial sampling differs in the experimental data acquisition, the procedure of surface wave method analysis is all based on three main steps, see Figure 3. Surface wave analysis is based on the natural dispersion of Rayleigh waves in the media layer. These steps include: 1) Acquisition of experimental data, i.e. seismic waves detected by mechanical sensors and recorded, 2) signal processing to construct experimental dispersion curves, and
3) Inversion of dispersion curve data to obtain 1D wave velocity profile [20]. The manufacture of dispersion curves is a very critical step to accurately calculate the shear velocity profile. The specification and accuracy of the dispersion curve are important properties that determine the accuracy of the inversion of the shear wave velocity profile [23].

\section{Acquisition}

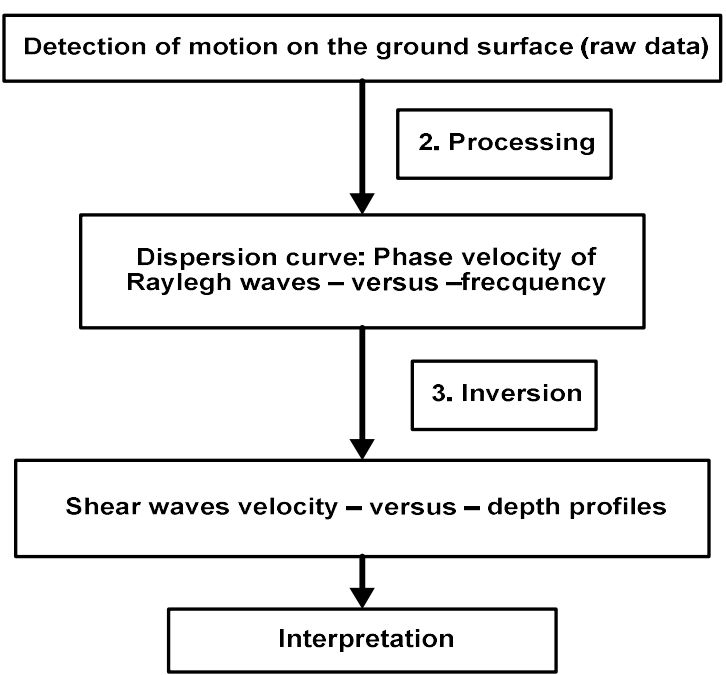

Figure 4. General procedure flows in surface wave methods: Acquisition, Processing, and Inversion.

Observation data processed to obtain $S$ wave velocity (Vs) profile as function of depth. The process is consecutively as follows: 1) Contains data in SEG-2 format, 2) Data is converted to DAT format, 3) Includes field geometry data, 4) Dispersed dispersion,
5) extracts dispersion curves, and 6) inverses (Figure 4). Result of inversion process, the S-1-D wave velocity profile, validated with the local outcrop thickness. Lithological interpretation of the Vs profile against depth 
based on several lithology classification reference tables such as [9-11].

Although the scale is different, this surface wave method is based on a principle that depends on vertical heterogeneous media. The wavelength (low frequency) of the Rayleigh wave penetrates the inner layer (R2) as in Figure 2. The speed of this wave is influenced by material properties at greater depth and also more informative. Conversely, the short-wavelength (highfrequency) Rayleigh wave propagates in the shallow layers (R1) near the surface and contains information about the mechanical properties of the shallow layers.

The propagation speed (called the phase velocity) of the surface wave is dependent on frequency or wavelength (this property is called dispersion). This unique characteristic is generated for different wavelengths for each frequency that is propagated [14]. The shear wave velocity of the subsurface can be obtained by back calculation process using dispersion curve. Because of this property, the surface wave method is based on the elastic wave equation and this analysis is performed completely in the frequency domain.

Body waves (P and S) and surface waves (Rayleigh, Love, etc.) propagate when seismic waves are generated at or near the earth's surface. Wave bodies propagate through the entire body of the earth, while surface waves propagate along (or near) the surface of the earth. If the seismic source is vertical (impulsive or swept), then the surface wave type generated is Rayleigh wave, or more commonly called ground roll. Ground roll occurs more than two-thirds $(2 / 3)$ of the generated seismic energy and is usually most dominant on multichannel recordings. Ground roll is the most effective type of surface wave in a surface seismic survey [14]. Therefore, most surface wave methods use active source by measuring Rayleigh wave phase velocity as a function of frequency [8]. The MASW measures Rayleigh waves and provides information throughout the depth range of the investigation. This leads to an evaluation of near surface velocity profiles.

\section{Results}

Figure $5 \mathrm{a}$ is one of the recordings of MASW result of Aik Berik field acquisition in shot 6. Shot 6 is done at source position 6.7 $\mathrm{m}$, with record length $1024 \mathrm{~ms}$ and sampling rate $125 \mu \mathrm{s}$. The recording data $\mathrm{f}(\mathrm{x}, \mathrm{t})$ is transformed to $\mathrm{f}-\mathrm{v}$ to obtain the $\mathrm{f}-\mathrm{v}$ dispersion curve as in Fig. $6 \mathrm{~b}$. On the f-v curve (Figure $6 \mathrm{~b}$ ) the picking is as indicated by the red dots. The picking result is the main input in order to make inversion. Initial model was built with an input frequency limits, depth, number iterations and limit of the error. Result of the inversion is obtained the velocity profile to depth (Figure 5c).

Figure 5 show the MASW results show the vertically distribution of $\mathrm{S}$ and $\mathrm{P}$ waves. The distribution of $S$ wave velocity is relatively heterogeneous from depth $(0$ 15.3) $\mathrm{m}$ i.e. (177 - 352) $\mathrm{m} / \mathrm{s}$ and $\mathrm{Vp}(1486$ 1681) $\mathrm{m} / \mathrm{s}$. Variation of velocity of $S$ and $P$ wave indicates that the material composition in the range of depth is quite varied. While for depths more than $15 \mathrm{~m}$, the velocity distribution Vs (266 - 352) m/s and Vp (1586 - 1681) $\mathrm{m} / \mathrm{s}$ is relatively homogeneous which means the material composition at that depth is homogeneous. These results are validated with local outcrops, then we interpret and classify them into two groups based on classification table published by [ $9-11]$. The following describes the velocity profiles for average depth (Table 2 and Figure 7).

Figure 6 is the two outermost outcrops at the MASW data acquisition location i.e. in the Benang Stokel (Fig. 6a) and in Barabali (Fig. 6b). The position of Benang Stokel is $\left(8^{\circ}\right.$ $32^{\prime} 1.71^{\prime \prime}$ S, $116^{\circ} 20^{\prime} 6.01^{\prime \prime}$ E) and 579 m.a.s.l of elevation is relatively closer to Mount Rinjani (sediment source). Barabali ( $8^{\circ} 34^{\prime} 4.31$ "S, $116^{\circ} 18^{\prime} 3.52^{\prime \prime} \mathrm{E}$ with an elevation 336 m.a.s.l) is farthest location from the source of sediment in the southern.

The outcrop of Benang Stokel has 5 layers, i.e. clay with $0.35 \mathrm{~m}$ thick, clay with clastic sand inserted $0.60 \mathrm{~m}$ thick, grain of pumice with $0.30 \mathrm{~m}$ thick, $0.50 \mathrm{~m}$ thick volcanic ash, and irregular coarse pumice, bluish in color, thickness more than one meter visible. The outcrop in Barabali (Figure $6 \mathrm{~b})$ consists of 4 layers, $0.30 \mathrm{~m}$ thick clay, 
grain of pumice inserted sandstone $0.35 \mathrm{~m}$ thick, volcanic ash $0.15 \mathrm{~m}$ thick, and brownish brownish pellet, thickness greater than $0.45 \mathrm{~m}$.

The two outcrops in Figure 6 have different physical and physical characteristics. Fig. 6a is closer to a higherelevation source (579 m.a.s.l). Based on its physical character, the precipitate deposits in Benang Stokel are colored bluish, coarse, pointy and coarse grained, the shapes vary from very pointed to pointy. Grain size also varies, ranging from $3 \mathrm{~mm}$ to $5 \mathrm{~m}$ or more. The stone in this location is very axis, this shows that the material is cooling very quickly, causing the atoms inside it not able to arrange themselves to form crystals. The thickness of the layer is thicker than that in Barabali which falls further. The outcrop in Barabali (Figure $6 b$ ) is relatively farther from Mount Rinjani and is at a lower elevation (336 m.a.s.l). Pumice deposite in Barabali location furthest to the south, has the character: brownish color, a granular matrix, smooth, shaped opal to the ball, less shaft and dominated by grain less than $2 \mathrm{~mm}$ of size. The thickness of the precipitate is thinner than the thickness of the layer in the Benang Stokel which is closer to the source.

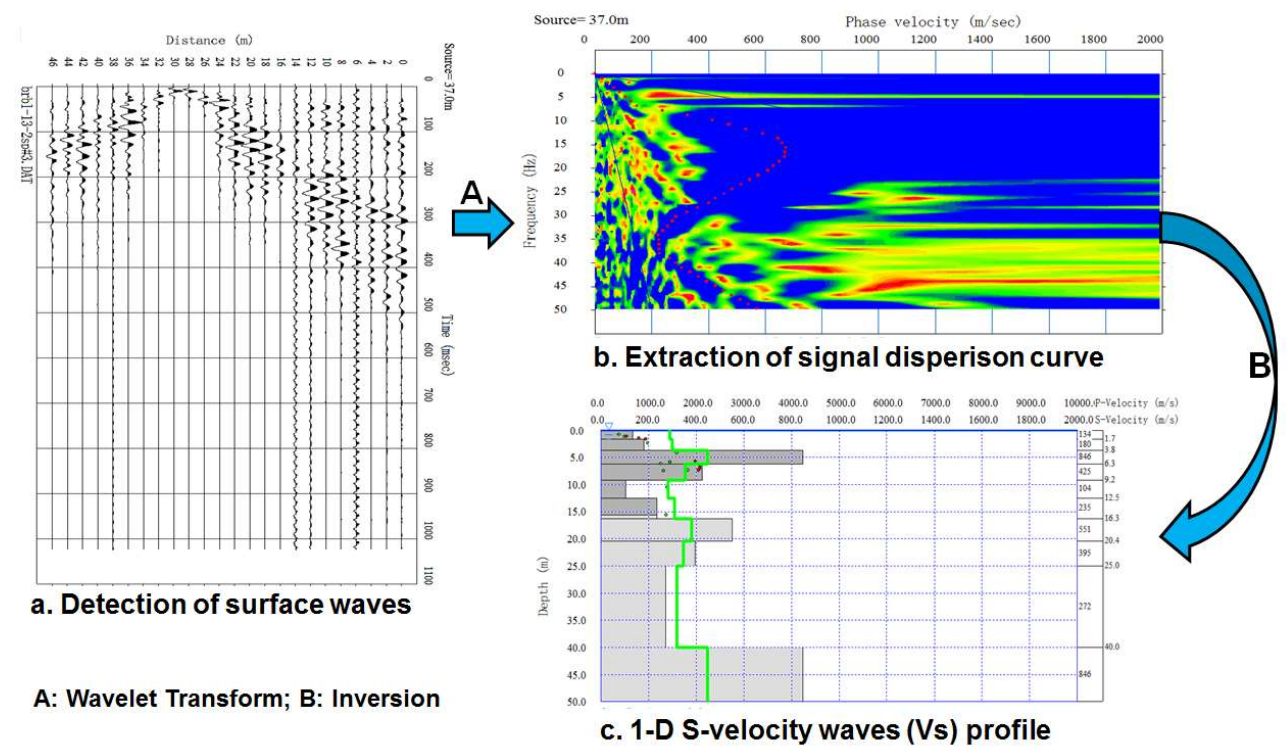

Figure 6. A normal data processing procedure with one field record of the MASW method. a. Detection of surface waves in $f(x, t)$ domains. $b$. The multi-channels record is first transformed into the $f$ - $v$ domain (the dispersion image) to extract the fundamental-mode dispersion curve (A). c. Inversion, where the curve is used as a reference to find a 1-D Vs profile whose theoretical curve matches the extracted (experimental) curve most closely (B). 


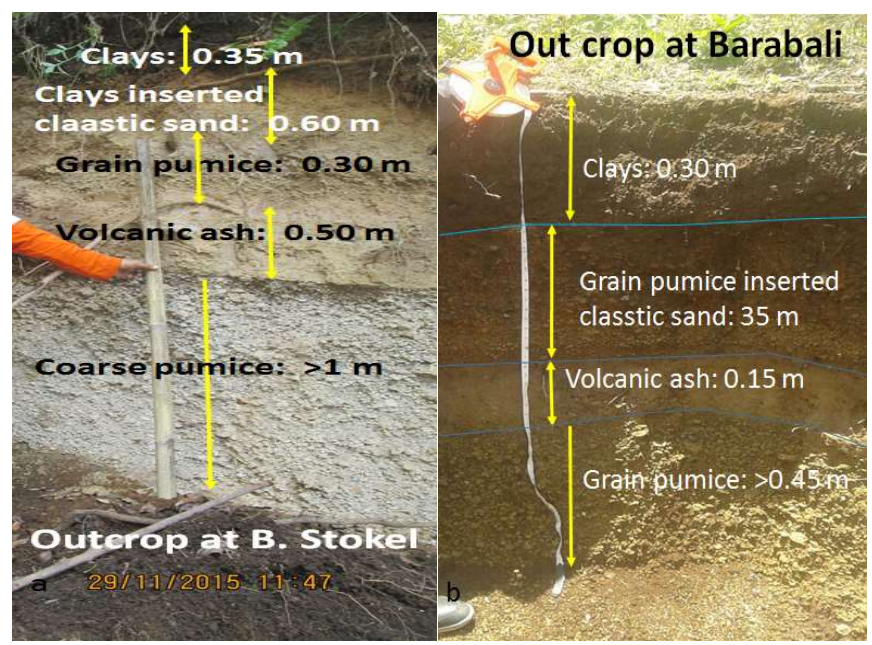

Figure 6. Locally Outcrop of rock at: a. Benang Stokel. b. Barabali. The Stratigraphic characteristics of the two outcrops differ, where the outline of the Benang Stokel is closer to the source than Barabali's outcrop (Photos by Authors).

\section{Discussion}

We conducted a observation in six locations in the Southern Area of Mount Rinjani, in May 2017. In each location 27 shots and 3 stacks were performed, resulting in a total of 486 data recorded. Result of processing data from each location, averaging, validating with outcrops, and interpreting and classifying sites to obtain a depth-velocity profile as in Table 2 and Figure 7.

Table 2 is presenting velocity $\mathrm{Vs}, \mathrm{Vp}$, and lithology interpretations of MASW observations in the Southern Region of Mount Rinjani. All locations show similar site class patterns based on the IBC 2009 classification (ICC, 2009), NEHRP (2003), and TSC (1998) to obtain three classes i.e. site class $E, D$, and $C$ respectively from the local soil surface. This shows that the settling pattern of the eruption of Mount Rinjani takes place in the same way and in relatively the same time. The vertical directional velocity distribution of each $\mathrm{Vp}$ between $(1437$ - 1775) $\mathrm{m} / \mathrm{s}$ and Vs between $(89-564) \mathrm{m} / \mathrm{s}$.

This MASW method is powerful enough to delineate the subsurface substrate strata in the undifferentiated and weathered areas especially on the slopes for shallow depths. However, it is less effective in imaging deeper structures, one of the causes of high frequency $(10 \mathrm{~Hz})$ and small geoponic spaces, in contrast to targets (thin films). In the future, should be combined with other techniques such as passive seismic, GPR, and geoelectric resistivity. 
Table 2. Shear and pressure waves velocities and its lithology interpretation in south region of Mount Rinjani

\begin{tabular}{|c|c|c|c|c|c|}
\hline Layer & $\begin{array}{l}\text { Vp_ave } \\
(\mathrm{m} / \mathrm{s})\end{array}$ & $\begin{array}{l}\text { Vs_ave } \\
(\mathrm{m} / \mathrm{s})\end{array}$ & $\begin{array}{l}\text { Depth_ave } \\
\text { (m) }\end{array}$ & $\begin{array}{l}\text { Site } \\
\text { class }\end{array}$ & Lithology Interpretation \\
\hline \multicolumn{6}{|c|}{ 1. Barabali } \\
\hline 1 & 1500 & 139 & 1.74 & \multirow[t]{2}{*}{$\mathrm{E}$} & $\begin{array}{l}\text { Clays }(0.35 \mathrm{~m}) \text {, grain pumice and Clastic sand }(0.3 \mathrm{~m}) \text {, ash } \\
\text { volcanic }(0.15 \mathrm{~m})\end{array}$ \\
\hline 2 & 1510 & 144 & 3.92 & & Grain pumice $(0.45 \mathrm{~m})$ \\
\hline 3 & 1950 & 558 & 6.50 & \multirow[t]{2}{*}{$\mathrm{C}$} & $\begin{array}{l}\text { Highly weathered soft metamorphic rocks and cemented } \\
\text { sedimentary rocks with planes of discontinuity. }\end{array}$ \\
\hline 4 & 1790 & 384 & 9.50 & & Medium dense sand and gravel, stiff clay, silty clay \\
\hline 5 & 1600 & 228 & 12.92 & \multirow{3}{*}{$\mathrm{D}$} & \multirow{3}{*}{$\begin{array}{l}\text { Soft, deep alluvial layers with high water table, Loose sand, soft } \\
\text { clay, silty clay. }\end{array}$} \\
\hline 6 & 1520 & 214 & 16.84 & & \\
\hline 7 & 1650 & 330 & 21.08 & & \\
\hline 8 & 1620 & 384 & 25.84 & $\mathrm{C}$ & Medium dense sand and gravel, stiff clay, silty clay. \\
\hline 9 & 1680 & 313 & 32.00 & $\mathrm{D}$ & $\begin{array}{l}\text { Soft, deep alluvial layers with high water table, Loose sand, soft } \\
\text { clay, silty clay. }\end{array}$ \\
\hline \multicolumn{6}{|c|}{ 2. Dasan Baru } \\
\hline 1 & 1550 & 168 & 2.40 & $\mathrm{E}$ & $\begin{array}{l}\text { Clays }(0.25 \mathrm{~m}) \text {, Grain pumice }(0.1 \mathrm{~m}) \text {, ash volcanic }(0.25 \mathrm{~m}) \text {, Grain } \\
\text { pumice }(0.1 \mathrm{~m}) \text {, ash volcanic }(0.15 \mathrm{~m}) \text {, grain pumice }(0.4 \mathrm{~m})\end{array}$ \\
\hline 2 & 1467 & 256 & 5.40 & $\mathrm{D}$ & $\begin{array}{l}\text { Soft, deep alluvial layers with high water table, Loose sand, soft } \\
\text { clay, silty clay. }\end{array}$ \\
\hline 3 & 1742 & 426 & 9.03 & \multirow{7}{*}{ C } & \multirow{7}{*}{$\begin{array}{l}\text { Highly weathered soft metamorphic rocks and cemented } \\
\text { sedimentary rocks with planes of discontinuity, medium dense } \\
\text { sand and gravel }\end{array}$} \\
\hline 4 & 1717 & 389 & 13.27 & & \\
\hline 5 & 1900 & 564 & 18.10 & & \\
\hline 6 & 1750 & 453 & 23.50 & & \\
\hline 7 & 1708 & 417 & 29.47 & & \\
\hline 8 & 1675 & 380 & 36.10 & & \\
\hline 9 & 1683 & 405 & 40.00 & & \\
\hline \multicolumn{6}{|c|}{ 3. Teratak } \\
\hline 1 & 1493 & 194 & 1.81 & \multirow{9}{*}{$\mathrm{D}$} & Clays inserted pumice $(1.3 \mathrm{~m})$ \\
\hline 2 & 1500 & 202 & 4.06 & & Grain pumice $(2 \mathrm{~m})$ \\
\hline 3 & 1514 & 216 & 6.74 & & \multirow{7}{*}{$\begin{array}{l}\text { Stiff soil, soft, deep alluvial layers with high water table, Loose } \\
\text { sand, soft clay, silty clay }\end{array}$} \\
\hline 4 & 1536 & 245 & 9.86 & & \\
\hline 5 & 1514 & 220 & 13.40 & & \\
\hline 6 & 1521 & 198 & 17.46 & & \\
\hline 7 & 1493 & 184 & 21.86 & & \\
\hline 8 & 1493 & 181 & 26.79 & & \\
\hline 9 & 1529 & 201 & 34.29 & & \\
\hline \multicolumn{6}{|c|}{ 4. Aik Berik } \\
\hline 1 & 1437 & 89 & 1.34 & $\mathrm{E}$ & \multirow{5}{*}{ PDC, clays, classtic sand and inserted grain pumice $( \pm 20 \mathrm{~m})$} \\
\hline 2 & 1553 & 225 & 3.28 & \multirow{8}{*}{$\mathrm{D}$} & \\
\hline 3 & 1537 & 207 & 5.58 & & \\
\hline 4 & 1584 & 259 & 8.30 & & \\
\hline 5 & 1545 & 229 & 11.33 & & \\
\hline 6 & 1535 & 224 & 14.72 & & \multirow[t]{4}{*}{ Medium dense clastic sand and gravel, stiff clay, silty clay } \\
\hline 7 & 1537 & 220 & 18.47 & & \\
\hline 8 & 1524 & 215 & 22.59 & & \\
\hline 9 & 1573 & 255 & 30.63 & & \\
\hline
\end{tabular}




\begin{tabular}{|c|c|c|c|c|c|}
\hline Layer & $\begin{array}{c}\begin{array}{c}\text { Vp_ave } \\
(\mathbf{m} / \mathbf{s})\end{array} \\
\end{array}$ & $\begin{array}{c}\text { Vs_ave } \\
(\mathbf{m} / \mathbf{s})\end{array}$ & $\begin{array}{c}\text { Depth_ave } \\
(\mathbf{m})\end{array}$ & Site class & Lithology Interpretation \\
\hline \multicolumn{6}{|c|}{ 5. Benang Stokel } \\
\hline 1 & 1480 & 94 & 1.40 & \multirow[t]{2}{*}{ E } & $\begin{array}{l}\text { Clays }(0.35 \mathrm{~m}) \text {, volcanic ash inserted of classtic sand }(0.6 \mathrm{~m}) \text {, grain } \\
\text { pumice }(0.3 \mathrm{~m})\end{array}$ \\
\hline 2 & 1510 & 166 & 3.10 & & Volcanic ash $(0.5 \mathrm{~m})$ \\
\hline 3 & 1550 & 212 & 5.20 & \multirow{7}{*}{$\mathrm{D}$} & Coarse grain pumice $(>1 \mathrm{~m})$ \\
\hline 4 & 1530 & 198 & 7.60 & & \multirow{6}{*}{$\begin{array}{l}\text { Soft, deep alluvial layers with high water table, loose sand, soft clay, } \\
\text { silty clay }\end{array}$} \\
\hline 5 & 1540 & 199 & 10.40 & & \\
\hline 6 & 1520 & 181 & 13.50 & & \\
\hline 7 & 1540 & 192 & 17.00 & & \\
\hline 8 & 1530 & 190 & 20.80 & & \\
\hline 9 & 1520 & 184 & 33.30 & & \\
\hline \multicolumn{6}{|c|}{ 6. Benang Kelambu } \\
\hline 1 & 1600 & 226 & 2.80 & \multirow{2}{*}{$\mathrm{D}$} & \multirow[b]{2}{*}{ Clays, classtic sand, and inserted grain pumce $(6.3 \mathrm{~m})$} \\
\hline 2 & 1569 & 234 & 6.30 & & \\
\hline 3 & 1775 & 424 & 10.40 & \multirow{7}{*}{$\mathrm{C}$} & \multirow{7}{*}{$\begin{array}{l}\text { Very dense soil and soft rock: highly weathered soft metamorphic } \\
\text { rocks and cemented sedimentary rocks with planes of discontinuity. } \\
\text { Medium dense sand and gravel }\end{array}$} \\
\hline 4 & 1656 & 368 & 15.30 & & \\
\hline 5 & 1675 & 364 & 20.80 & & \\
\hline 6 & 1738 & 391 & 27.10 & & \\
\hline 7 & 1769 & 403 & 34.00 & & \\
\hline 8 & 1738 & 396 & 41.70 & & \\
\hline 9 & 1681 & 370 & & & \\
\hline
\end{tabular}
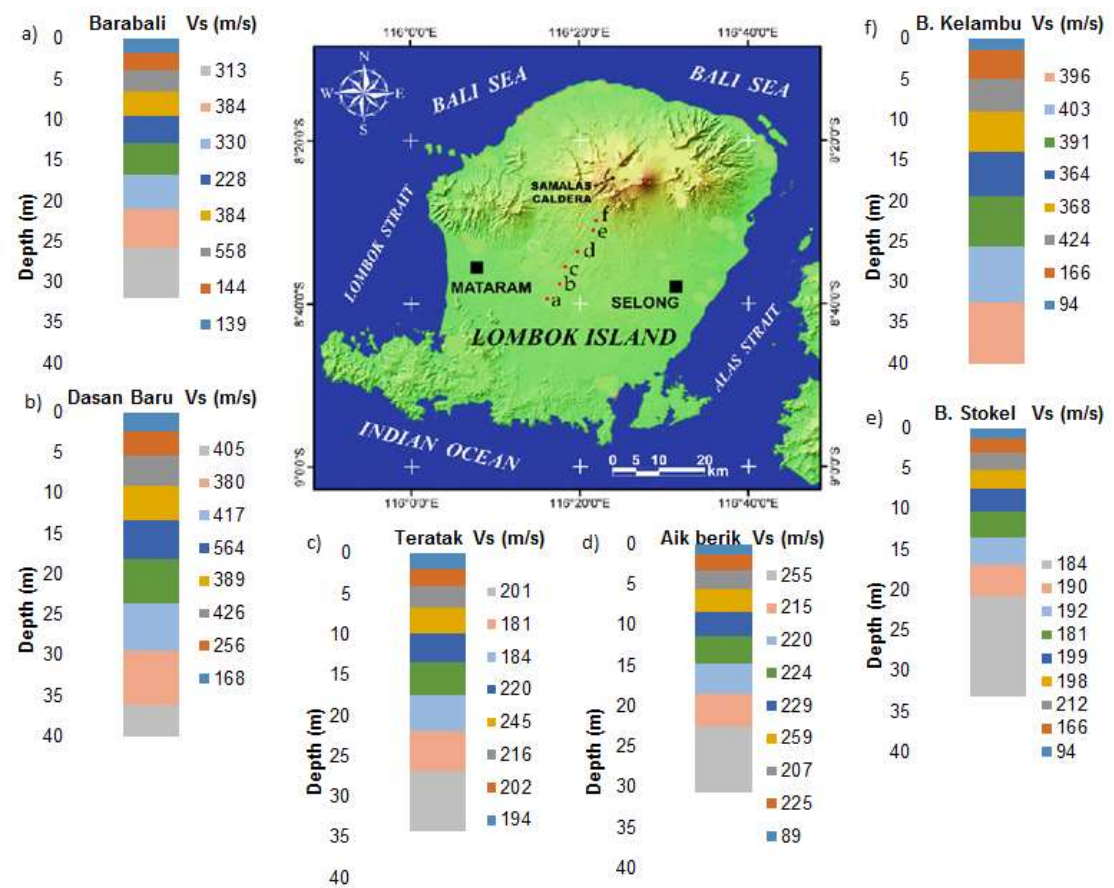

B. Stokel Vs (mis)

40

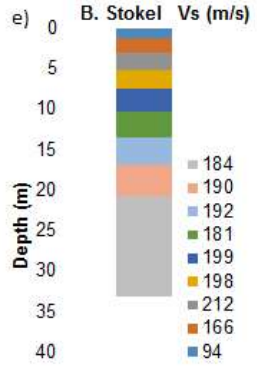

Figure 7. Log litology profile in the southern region of Mount Rinjani. Consecutive survey location, from the furthest, a) Barbali, b) New Dasan, c) Teratak, d) Aik Berik, e) Stokel yarn, and f) Kelmabu Yarn. Log lithology color is based on Lithclass polygon colors, USGS [24]. 


\section{Conclusion}

MASW method has used and physical characteristics of volcanic deposits distribution, in southern region of Mount Samalas and Mount Rinjani. The physical characteristics of the volcanic deposits, especially the sandstone, consist of three types i.e. fine-grained, less axle, brownish, coarse-grained, tapered, bluish, very axis, and a PDC with thickness of more than $20 \mathrm{~m}$. Physical characteristics that obtained are Vs, Vp, layer thickness and site class. Site class E with speed Vs: $(89-168) \mathrm{m} / \mathrm{s}$ and Vp: $(1437$ - 550) m/s, site class D speed Vs: $(181$ - 330) m/s and Vp: $(1467-1680)$ $\mathrm{m} / \mathrm{s}$, and site class C, have Vs: $(368$ - 564) m/s and Vp: $(1620$ - 1950) m/s. Thick site class E (2.4 3.92) $\mathrm{m}$ is top soil in Barabali area, Dasan Baru, Aik Berik, and Benang Stokel. Class D is most dominant across the study sites whit thickness $(3-34.29) \mathrm{m}$, while class $C$ generally occupies the innermost layer of all locations. Thickness of class $C$ layer $(5.58-31.30) \mathrm{m}$. In the future, there will be the volcanic deposits and analysis of the dynamics of the eruption of Mount Samalas 1257 AD, for prediction and mitigations in the future. This method useful for prediction of dynamics of eruptions and landslide mitigation.

Author Contributions: H.H., T.G.A., S.M., and A.T. Conceived and designed the acquisition; S.M., and A.T. performed the experiments; H.H. described the outcrops; H.H., T.G.A., M.M, and S.M. processing and analyzed the data; H.H., T.G.A., and M.M wrote the paper with contributions from all co-authors; S.M. and A.T. reviewed and edited the paper.

\section{Funding}

The source of all funding of this research comes from DP2M Kemenristek Dikti Indonesian.

\section{Acknowledgements}

The authors which to thank many colleagues and students from the Universitas Mataram, helped collect data, and Muh. Alfaris, S.Si. and Agus Wahid H., S.Si. were instrumtal in data collection. The authors which also to thank Reviewers for their suggestions and contributors which improved the quality of the paper. Editors are thanked for their comments and for the editorial handling of this paper.

Conflicts of Interest: The authors declare no conflict of interest.

\section{References}

1. Van Dam, R.L., Landform characterization using geophysics-Recent advances, applications, and emerging tools. Geomorphology, 2012, 137, 57-73. doi:10.1016/j.geomorph, 09,005.

2. Socco, L. V., Foti, S., \& Boiero, D.: Surface-wave analysis for building near-surface velocity models - Established approaches and new perspectives. Geophysics, 2010, 75 (5), 75A83 75A102.

3. E. G. Diaz-Segura, Effect of MASW field configuration on estimation of shear wave propagation velocity in sloped terrain, Géotechnique Letters, 2015, 5(1), pp. 21-27, https://doi.org/10.1680/ geolett.14.00070

4. Wacana, L., Babad-Lombok, Departemen Pendidikan dan Kebudayaan Proyek Penerbitan Buku Bacaan Sastra Indonesia dan Daerah, Jakarta, Indonesia, 1979, Volume 274, p. 66. Available online: https://openlibrary.org/books/OL2703706M/Babad_Lombok

5. Hiden, Kirbani Sri Brotopuspito, Danang Sri Hadmoko, Frank Lavigne, Kim Boilot Airaksinen, Bachtiar W. Mutaqin, Nugroho D. Hananto, Lina Handayani, Yayat Sudrajat, and Wiwit Suryanto: The Isopach Mapping of Volcanic Deposits of Mount Samalas 1257 AD Based on the 
Values of Resistivity and Physical Properties, Geociences, 2017, 7, 67. doi: 10.3390/geosciences7030067

6. Lavigne, F., Degeai, J.-P.; Komorowski, J.-C.; Guillet, S.; Robert, V.; Lahite, P.; Oppenheimer, C.; Stofflel; M.; Vidal, C.M.; Surono: Source of the Great A.D.1257 Mystery Eruption Unveiled, Samalas Volcano, Rinjani Volcanic Complex, Indonesia, PNAS, 2013, 110, doi: 10.1073/pnas.1307520110

7. Mangga, S.A., Atmawinata, S.; Hermanto, B.; Setyonugroho, B.; Amin, T.C., Geological Map of the Lombok Sheet, West Nusa Tenggara, Indonesia, 1994

8. Boore, D.M, Determining Subsurface Shear-Wave Velocities, A Review, Third International Symposium on the Effects of Surface Geology on Seismic Motion Grenoble, France, 2006, p: 103.

9. International Building Code, 2009 IBC, (International Building Code) International Code Council, INC., 2009.

10. NEHRP, Shear wave Velocity Map-Global Vs30 Map (USGS), Source of Global VS Map Server: U.S. Geological Survey, 2003, http://earthquake.usgs.gov/hazards/apps/vs30/

11. TSC, Ministry of Public Works and Settlement Government of Republic of Turkey, Specification for Structures to be built in Disaster Areas, 1998.

12. G. Coulouma, K. Samyn, G. Grandjean, S. Follain, P. Lagacherie, Combining seismic and electric methods for predicting bedrock depth along a Mediterranean soil toposequence, Geoderma, 2012, Volume 170, Pages 39 - 47, https:// doi.org/10.1016/j.geoderma.2011.11.015

13. Park, C. B., and Shawver, J. B., MASW Survey Using Multiple Source Offsets. In D. K. Butler (Ed.), Proceedings of the Symposium on the Application of Geophysics to Engineering and Environmental Problems, Denver, CO., Environment and Engineering Geophysical Society, 2009, pp. 15-19.

14 Park, C. B., Miller, R. D., Xia, J., Multichannel analysis of surface waves, Geophysics, 1999, 64, 800 - 808, http://dx.doi.org/10.1190/1.1444590

15 Fatima Gouveia, Isabel Lopes, and Rui Carrilho Gomes: Deeper Vs profile from joint analysis of Rayleigh wave data, Engineering Geology, 2016, 202: 85 - 98

16. Stokoe II KH, Wright GW, Bay JA, Roesset JM., Characterization of geotehchnical sites by SASW method. In: Woods RD, editor. Geophysical characterization of sites, ISSMFE Technical Committe New Delhi: Oxford Publishers, 1994.

17. W. J. Stephenson, J. N. Louie, S. Pullammanappallil, R. A. Williams, and J. K. Odum, Blind ShearWave Velocity Comparison of ReMi and MASW Results with Boreholes to $200 \mathrm{~m}$ in Santa Clara Valley, Implications for Earthquake Ground-Motion Assessment, Bulletin of the Seismological Society of America, 2005, Vol. 95, pp. 2506-2516, Doi: 10.1785/0120040240

18. Cheng, F., Xia, J., Xu,Y., Xu, Z., Pan, Y., A new passive seismic method based on seismic interferometry and multichannel analysis of surface waves, J. Appl. Geophys, 2015, 117, 126 135, http:// dx.doi.org/10.1016/j.jappgeo.2015.04.005.

19. Hayashi, K., Data Acquisition and Analysis of Active and Passive Surface Wave Methods, Sageep 20 Short, Course, 2003.

20. Xiaohui Jin, Barbara Luke, and Carlos Calderon-Macias, Role of Forward Model in SurfaceWave studies to delineate a Buried High-Velocity Layer, JEEG, 2006, volume 14, pp. 1-14

21. Jyant Kumar, A study on determining the theoritical dispersion curve for Rayleigh wave propgartion, Soil Dynamics and Earthquake Engineering, 2011, 31: 1196-1202

22. Park, C. B., Miller, R. D., \& Xia, J.: Offset and resolution of dispersion curve in multichannel analysis of surface waves (MASW), In Proceedings of the Symposium on the Application of 
Geophysics to Engineering and Environmental Problems 2001 (p. SSM4). Denver, CO., Environment and Engineering Geophysical Society, 2001.

23. Jianghai Xia, Richard D. Miller, and Choon B. Park: Estimation of near-surface shear-wave velocity by inversion of Rayleigh waves, Geophysics, 1999, Vol. 64, P. $691-700$.

24. Lithclass polygon colors - USGS, http://mrdata.usgs.gov/catalog/lithclass-color.php (accessed on 27 May 2017) 